\title{
Surface degradation behaviour of sodium borophosphate glass in aqueous media: Some studies
}

\author{
K V SHAH ${ }^{\dagger}$, M GOSWAMI, S MANIKANDAN, V K SHRIKHANDE and \\ G P KOTHIYAL* \\ Technical Physics \& Prototype Engineering Division, Bhabha Atomic Research Centre, Mumbai 400 085, India \\ ${ }^{\dagger}$ Present address: Department of Condensed Matter Physics \& Materials Science, \\ Tata Institute of Fundamental Research, Mumbai 400 005, India
}

\begin{abstract}
The degradation behaviour of phosphate glass with nominal composition, $40 \mathrm{Na}_{2} \mathrm{O}-10 \mathrm{BaO}-x \mathrm{~B}_{2} \mathrm{O}_{3}-$ $(50-x) \mathrm{P}_{2} \mathrm{O}_{5}$, where $0 \leq x \leq 20 \mathrm{~mol} \%$, was studied in water, $\mathrm{HCl}$ and $\mathrm{NaOH}$ solutions at room temperature to $60^{\circ} \mathrm{C}$ for different periods extending up to $300 \mathrm{~h}$. These glasses were synthesized by conventional melt-quench technique. Dissolution rates were found to increase with $\mathrm{B}_{2} \mathrm{O}_{3}$ content in the glass. The dissolution rates for the glass having $10 \mathrm{~mol} \% \mathrm{~B}_{2} \mathrm{O}_{3}$ were found to be $0.002 \mathrm{~g} / \mathrm{cm}^{2}$ and $0.015 \mathrm{~g} / \mathrm{cm}^{2}$ in distilled water and $5 \% \mathrm{NaOH}$ solution, respectively, at room temperature after $225 \mathrm{~h}$ of total immersion period, whereas it increased considerably to $0.32 \mathrm{~g} / \mathrm{cm}^{2}$ in $5 \% \mathrm{NaOH}$ at $60^{\circ} \mathrm{C}$ after $225 \mathrm{~h}$. However, glass samples with $x=15$ and $20 \mathrm{~mol} \% \mathrm{~B}_{2} \mathrm{O}_{3}$ were dissolved in $5 \% \mathrm{HCl}$ solution after $5 \mathrm{~h}$ immersion. The degradation behaviour has been correlated with the structural features present in the glass. The optical microscopy of the corroded surface revealed that the corrosion mechanism were different in acid and alkali media.
\end{abstract}

Keywords. Borophosphate glass; surface degradation; aqueous media.

\section{Introduction}

Phosphate glasses and glass-ceramics are useful for applications such as bone transplantation, glass-to-metal seals, containment of radioactive wastes, fast ion conductors, laser host materials etc (Brow 2000). They have a comparatively high transmission in the ultraviolet region compared to silicate and borate glasses (Brow 1996). They also have low glass transition and melting temperatures compared to silicate glasses (Brow and Tallant 1997). The network structure of simple phosphate glass consists of $\mathrm{P}$ tetrahedra linked to neighbouring tetrahedra through bridging oxygen (BOs). Addition of $\mathrm{Al}^{3+}, \mathrm{B}^{3+}$, $\mathrm{Bi}^{3+}$, etc has been found to improve the chemical durability because of the formation and relative stability of $\mathrm{M}^{3+}-\mathrm{O}-\mathrm{P}$ bond (Tsuchiya and Moriya 1980). These ions modify various physical properties including thermomechanical and optical behaviour basically due to change in glass structural network through formation of crosslinked bonds.

Borophosphate glasses having improved durability are among the multi component glasses studied for various interesting applications. Alkali and silver borophosphate glasses have been developed for fast ion conducting applications (Kaushik and Hariharan 1987; Coppo et al 1996); zinc-calcium borophosphate glasses were studied as candidates for applications as low-melting glass sol-

*Author for correspondence (gpkoth@barc.gov.in) ders and glass-to-metal (GM) seals (Ma et al 1993; Harish Bhat et al 2001). The structure of borophosphate glasses was studied by NMR spectroscopy (Yun and Bray 1978) and it was found that both $\mathrm{BO}_{3}$ and $\mathrm{BO}_{4}$ structural units were present in the glass structure. The fraction of $\mathrm{BO}_{4}$ units in the glasses was also found out in this study, which is an important parameter in the context of improvement of durability of these glasses. The presence of $\mathrm{BO}_{3}$ and $\mathrm{BO}_{4}$ structural units affects the chemical bonding with the phosphate tetrahedra, which becomes important in determining the chemical durability of these glasses.

The corrosion studies on alkali alkaline earth phosphate glasses (Wilder 1980) revealed that corrosion resistance of these glasses to water attack was improved by small addition of $\mathrm{Al}_{2} \mathrm{O}_{3}$ and glasses with thermal expansion coefficients (TEC) greater than $200 \times 10^{-7} /{ }^{\circ} \mathrm{C}$ and glass transition temperatures, $T_{\mathrm{g}}$, below $400^{\circ} \mathrm{C}$ and melting points, below $600^{\circ} \mathrm{C}$ which could be hermetically sealed to aluminium alloys. Sodium borophosphate glass studies show an increase in $T_{\mathrm{g}}$ and decrease in TEC for $y=\mathrm{B} /(\mathrm{B}+\mathrm{P})=0-0 \cdot 5 \quad\left(\mathrm{~B}=\mathrm{B}_{2} \mathrm{O}_{3}\right.$ content in $\mathrm{mol} \%$, $\mathrm{P}=\mathrm{P}_{2} \mathrm{O}_{5}$ content in mol\%) where $\mathrm{BO}_{4}$ units dominate over $\mathrm{BO}_{3}$ units. The maximum TEC reported for sodium borophosphate glasses is $199 \times 10^{-7}$ for $y<0.5$. Therefore, it seems interesting to study the effect of $\mathrm{B}_{2} \mathrm{O}_{3}$ addition in sodium barium phosphate glass since the addition of boron oxide tends to improve the durability of sodium phosphate glass without any major change in the TEC of these glasses. In this work we report the degradation behaviour of sodium barium borophosphate glasses in water, 
acid and alkali media at room temperature and at $60^{\circ} \mathrm{C}$. To the best of our knowledge this data is new for phosphate glasses and the structural and physico-mechanical properties for these glasses are reported elsewhere (Shah et al 2006). We have prepared a vacuum seal using glass composition, $x=10 \mathrm{~mol} \%$ with Al metal, withstanding $10^{-6}$ Torr pressure and also carried out glass to metal interface study.

\section{Experimental}

Sodium borophosphate glasses having composition, $40 \mathrm{Na}_{2} \mathrm{O}-10 \mathrm{BaO}-x \mathrm{~B}_{2} \mathrm{O}_{3}-(50-x) \quad \mathrm{P}_{2} \mathrm{O}_{5}$, where $x=0$ $20 \mathrm{~mol} \%$ were prepared by conventional melt-quench technique as reported earlier (Shah et al 2006). Analytical grade reagents with no water of crystallization, $\mathrm{NaNO}_{3}$, $\mathrm{Ba}\left(\mathrm{NO}_{3}\right)_{2}, \mathrm{~B}_{2} \mathrm{O}_{3}$ and $\mathrm{NH}_{4} \mathrm{H}_{2} \mathrm{PO}_{4}$ were used as starting materials in such proportions that the $\mathrm{O} / \mathrm{P}$ ratio changed from 3.0-4.33. The initial charge $(30-40 \mathrm{~g})$ was thoroughly mixed and ground for $30-40 \mathrm{~min}$ in a mortar pestle and then calcined in an alumina crucible for 18-20 h by heating in a predetermined manner considering the decomposition temperatures of individual compounds at the maximum temperature of $600^{\circ} \mathrm{C}$. This charge was reground and calcined again at $600^{\circ} \mathrm{C}$ for $4 \mathrm{~h}$ in the same manner. The calcined charge was then melted in a platinum crucible using lowering and raising hearth furnace (Model OKAY 70R 10, M/s Bysakh and Co., Kolkata) and held at temperatures ranging from $750-800^{\circ} \mathrm{C}$ depending on the composition for $2 \mathrm{~h}$ for thorough mixing in air ambient. When the melt was thoroughly homogenized and attained the desirable viscosity, it was poured either onto a metal plate and pressed by a graphite disc or into graphite moulds. The glass was then annealed at appropriate temperatures (between 350 and $400^{\circ} \mathrm{C}$ ) for $3 \mathrm{~h}$ and stored in a desiccator prior to evaluation.

Powder XRD patterns of the glasses were recorded on JEOL 3080 Diffractometer using $\mathrm{Cu}-\mathrm{K}_{\alpha}$ radiation to ascertain the glassy nature of the samples. The weight loss of well-polished glass samples (degradation) was measured in distilled water, $5 \% \mathrm{HCl}$ and $5 \%$ sodium hydroxide $(\mathrm{NaOH})$ solution at room temperature and $60^{\circ} \mathrm{C}$. Separate samples were used for each medium. The samples were removed, dried and weighed after immersion time of $5 \mathrm{~h}$ or $24 \mathrm{~h}$ depending on the weight loss. The glass surfaces were also examined under microscope at 25 and $50 \mathrm{X}$ magnification to study the degradation if any at the surface of the glass samples. The weight loss was then calculated and dissolution rate was calculated using the following formula

$$
D=\frac{W_{0}-W_{\mathrm{t}}}{A t}
$$

where $W_{0}$ is the initial weight of glass sample in air, $W_{\mathrm{t}}$ the weight of glass sample after time $t, A$ the surface area and $t$ the time of measurement.

\section{Results and discussion}

XRD patterns for different glass samples are presented in figure 1 . These patterns confirm the glassy nature of the samples with broad peaks around $20-30^{\circ}$ and $40-50^{\circ}(2 \theta$ values). Figure 2 shows the plot of dissolution rates of glass samples of different contents of $x=5-20 \mathrm{~mol} \%$ in distilled water as a function of immersion time. It is evident from figure 2 that for glass with $x=5 \mathrm{~mol} \%$ the dissolution rate (degradation) is nearly constant throughout immersion for $260 \mathrm{~h}$ whereas, the glass with $x=10 \mathrm{~mol} \%$, shows similar dissolution rate up to $110 \mathrm{~h}$ which substantially increases with further immersion. The dissolution rates for glasses with $x=15$ and $20 \mathrm{~mol} \%$ start showing increase even after $30-40 \mathrm{~h}$ but the rate for glass with

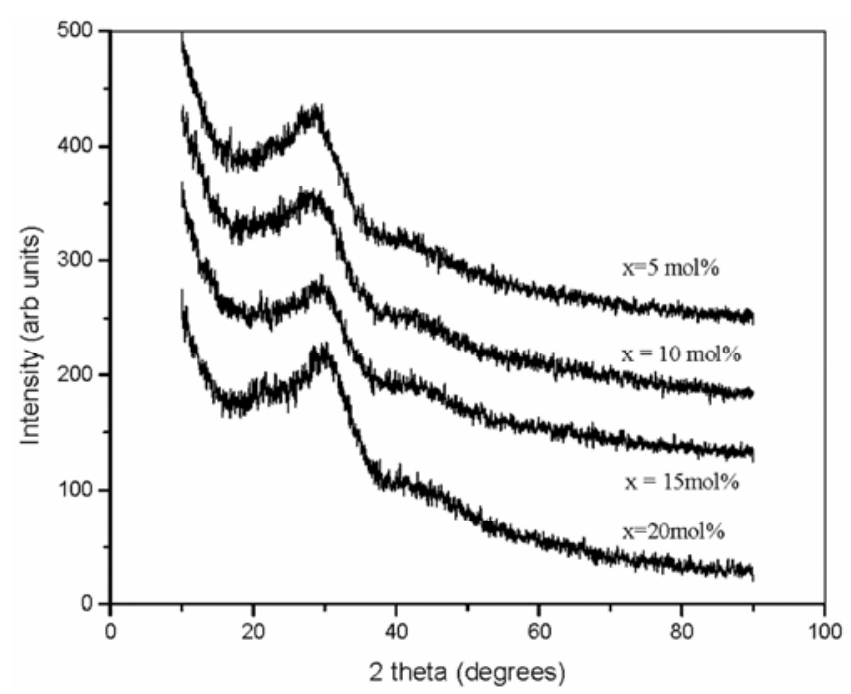

Figure 1. XRD plots of the different glass samples having nominal composition, $40 \mathrm{Na}_{2} \mathrm{O}-10 \mathrm{BaO}-x \mathrm{~B}_{2} \mathrm{O}_{3}-(50-x) \mathrm{P}_{2} \mathrm{O}_{5}$, where $x=0-20 \mathrm{~mol} \%$.

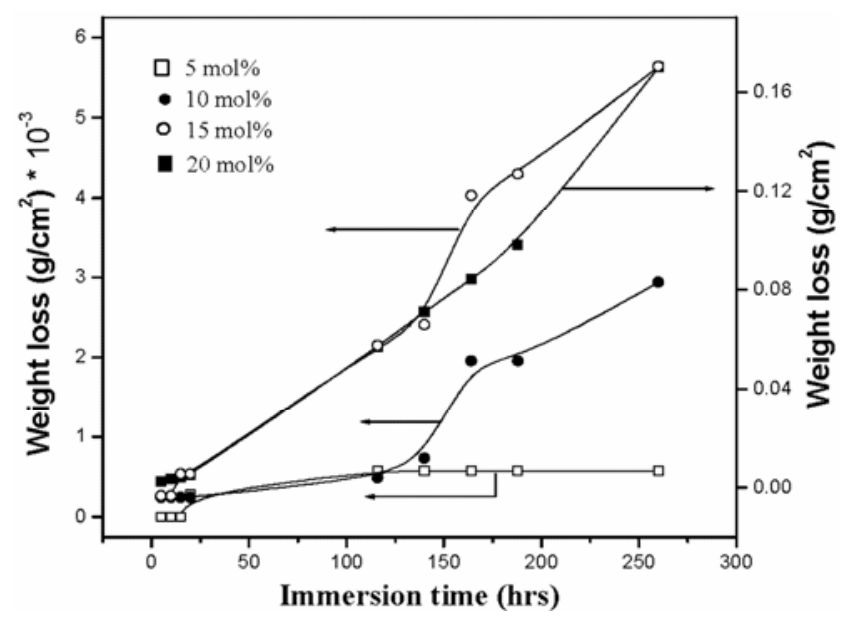

Figure 2. Dissolution of glass samples having composition $x=5-20 \mathrm{~mol} \%$ in distilled water at room temperature and at $25 \mathrm{X}$ magnification. 

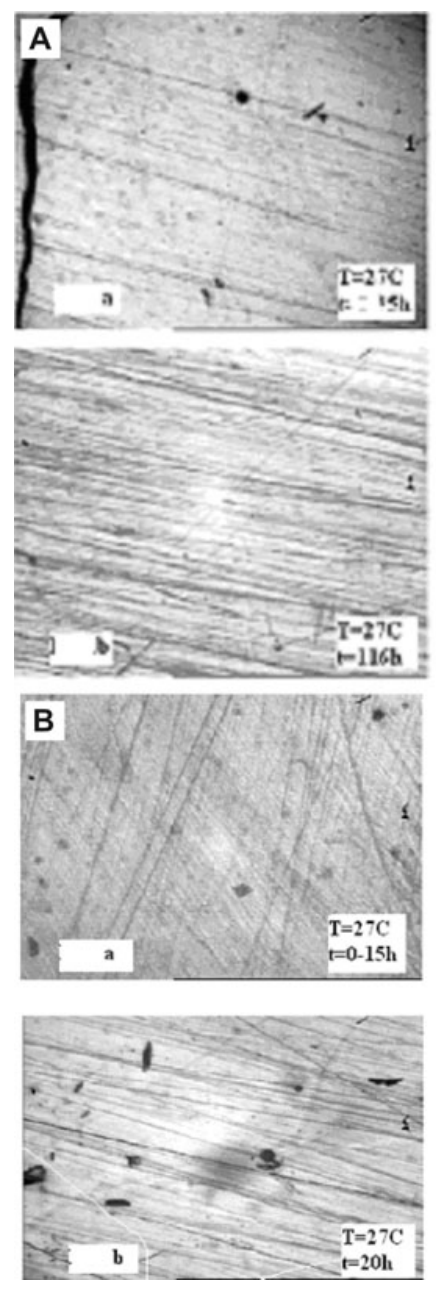
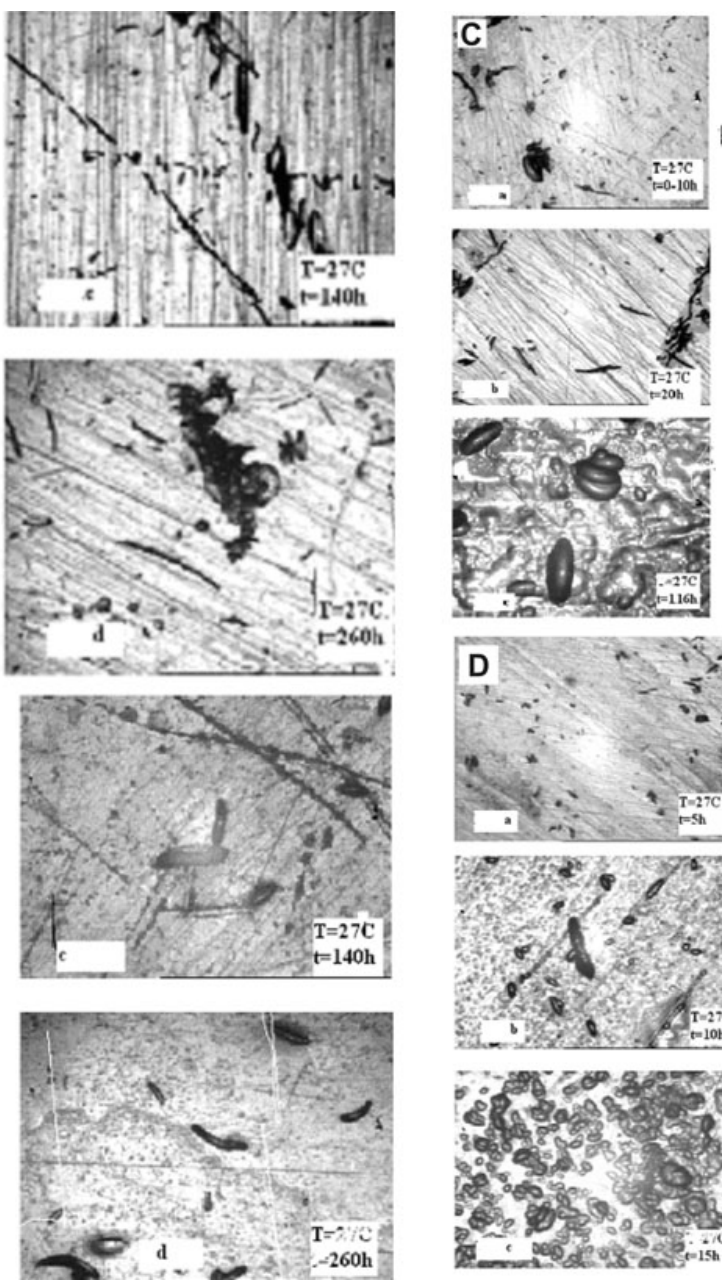
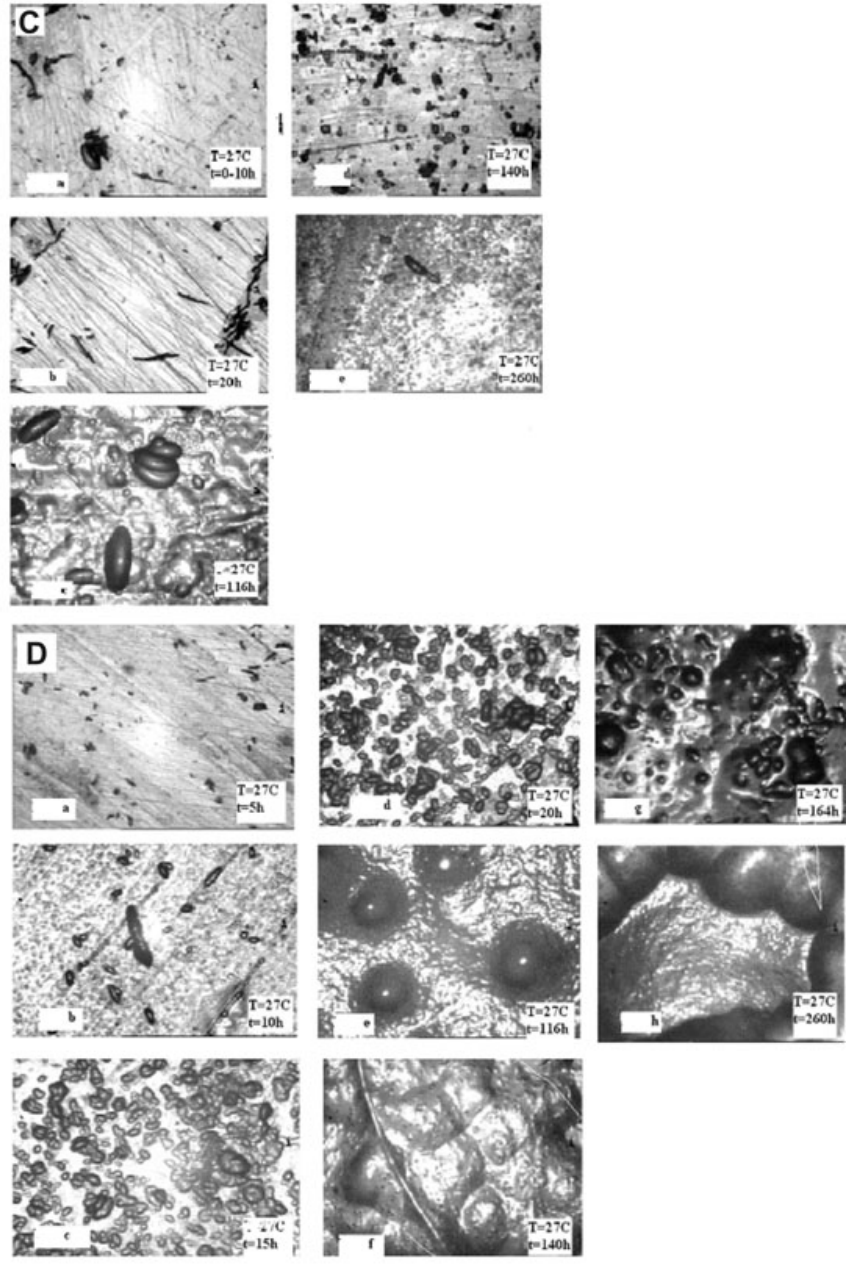

Figure 3. A. Morphology of the surface of the sample with $x=5 \mathrm{~mol} \%$ after different immersion times in distilled water and at 25X magnification, B. morphology of the surface of the sample with $x=10 \mathrm{~mol} \%$ after different immersion times in distilled water and at 25X magnification, $\mathbf{C}$. morphology of the surface of the sample with $x=15 \mathrm{~mol} \%$ after different immersion times in distilled water and at $25 \mathrm{X}$ magnification and $\mathbf{D}$. morphology of the surface of the sample with $x=20 \mathrm{~mol} \%$ after different immersion times in distilled water and at 25X magnification.

$x=20 \mathrm{~mol} \%$ increases to atleast two orders of magnitude. This shows that glass samples having lower $\mathrm{B}_{2} \mathrm{O}_{3}$ content are not greatly attacked by distilled water. Possible dissolution reactions in the aqueous medium are given in following equations (Gao et al 2004)

$$
\begin{aligned}
& \mathrm{Na}^{+}\left[\mathrm{BO}_{4}\right]^{-}+\mathrm{H}^{+} \mathrm{OH}^{-} \rightarrow \mathrm{H}^{+}\left[\mathrm{BO}_{4}\right]^{-}+\mathrm{Na}^{+} \mathrm{OH}^{-}, \\
& \mathrm{Na}^{+}\left[\mathrm{PO}_{4}\right]^{-}+\mathrm{H}^{+} \mathrm{OH}^{-} \rightarrow \mathrm{H}^{+}\left[\mathrm{PO}_{4}\right]^{-}+\mathrm{Na}^{+} \mathrm{OH}^{-}, \\
& \mathrm{B}_{2} \mathrm{O}_{3}+3 \mathrm{HOH} \rightarrow 2 \mathrm{H}_{3} \mathrm{BO}_{3},
\end{aligned}
$$

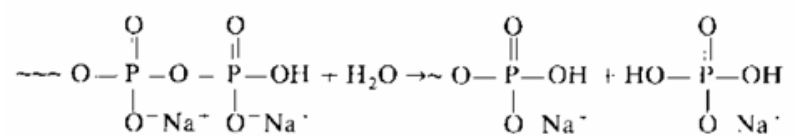

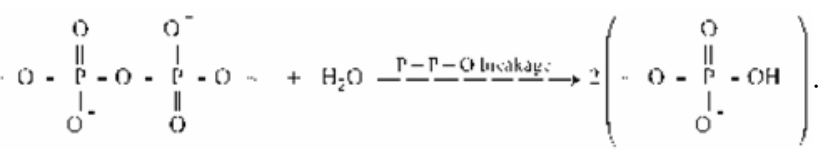

As $\mathrm{B}_{2} \mathrm{O}_{3}$ content in the glass increases, the metaphosphate chains are converted into orthophosphate structural units with the formation of $\mathrm{P}-\mathrm{OH}$ and $\mathrm{Na}^{+} \mathrm{OH}^{-}$bonds, which are relatively weak in nature, resulting in increase in the dissolution rate. $\mathrm{B}_{2} \mathrm{O}_{3}$ reacts with water and forms boric acid, which readily dissolves in water. It is also observed that with increase in $\mathrm{B}_{2} \mathrm{O}_{3}$ content, $\mathrm{BO}_{4}$ units are increased. $\mathrm{BO}_{4}$ structural units exist as $\mathrm{BO}_{4}^{-} \mathrm{Na}^{+}$units, which readily react with aqueous medium to form sodium borate, which is soluble in water or acidic medium. Thereby it increases the dissolution rate.

It is believed that $\mathrm{Na}^{+}$ions get dissolved in water solution and the solution becomes alkaline in nature due to increase in the $\mathrm{pH}$ value with increase in time of expo- 
sure. The alkaline nature of the solution breaks the glass network leading to pronounced leaching of the sample, thereby increasing the weight loss after immersion time of $140 \mathrm{~h}$, as seen in figure 2 .

It is seen that in general, dissolution rate increases with increase in $\mathrm{B}_{2} \mathrm{O}_{3}$ content as well as immersion time.

Figures 3A-D show the morphology of the surface of corroded glass samples of different compositions and different immersion period in distilled water.

The glass sample with $x=5 \mathrm{~mol} \%$ does not show any change in the surface morphology up to $116 \mathrm{~h}$ at room temperature (figures 3A.a and 3A.b). However, only small degradation is seen on prolonged immersion, after 140 and $260 \mathrm{~h}$ (figures 3A.c and 3A.d) at room temperature. In the case of glass sample with $x=10 \mathrm{~mol} \%$, there is a negligible change in the surface morphology up to $20 \mathrm{~h}$ immersion (figures 3B.a and 3B.b). But after 140 and $260 \mathrm{~h}$ of exposure it seems that thin layers are leached out (figures 3B.c and 3B.d).

The optical micrograph of the glass sample with $x=15 \mathrm{~mol} \%$ also shows that there is a negligible change in the surface morphology up to $20 \mathrm{~h}$ immersion, whereas, the glass surface is corroded considerably after $140 \mathrm{~h}$ (figure 3 C.c) and a thin layer seems to be leached out after $260 \mathrm{~h}$ (figure 3C.d).

In the case of glass sample, $x=20 \mathrm{~mol} \%$, the surface starts corroding even after $10 \mathrm{~h}$ of exposure (figure 3D.b). A large number of pits are formed as seen in figures 3D.c and 3D.d after $15 \mathrm{~h}$ immersion. The size of pits and in turn the corrosion increases with further increase in immersion time (figures 3D.e and 3D.f). A thicker layer appears to be leached out after $116 \mathrm{~h}$, which is evident from the increased weight loss.

Figure 4 shows the dissolution rate for glass samples with $x=5$ and $10 \mathrm{~mol} \%$ in $5 \% \mathrm{HCl}$ solution, as a function of immersion time at room temperature. It is seen that the

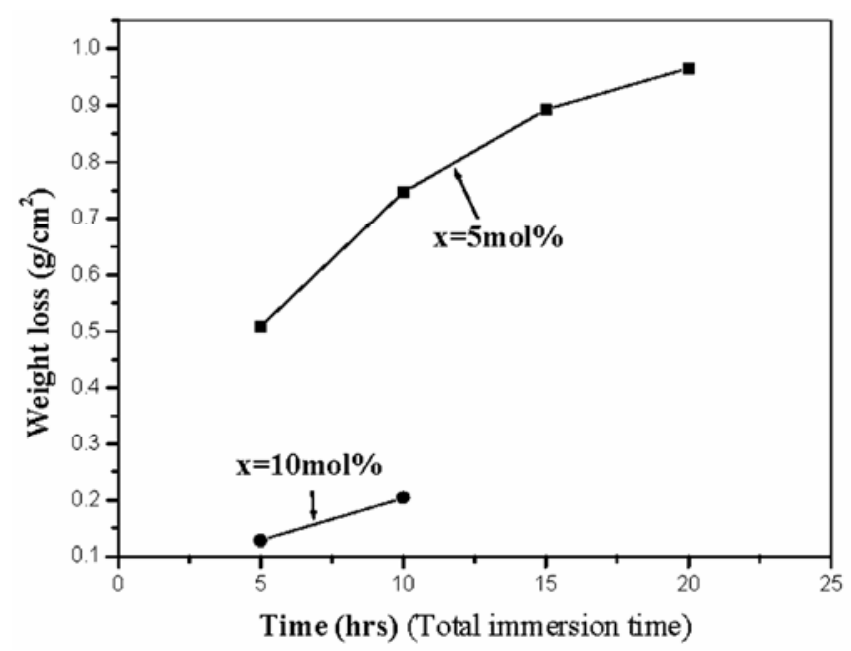

Figure 4. Dissolution rate as a function of TIT of glass samples $(x=5$ and $10 \mathrm{~mol} \%)$ at room temperature in acid medium. weight loss increases with increase in immersion. Glass samples with $x=15$ and $20 \mathrm{~mol} \%$ were dissolved in $5 \%$ $\mathrm{HCl}$ after $5 \mathrm{~h}$ of exposure.

Figures $5 \mathrm{~A}$ and $\mathrm{B}$ show the optical micrographs of glass samples with $x=5$ and $10 \mathrm{~mol} \%$, respectively immersed in $5 \% \mathrm{HCl}$ at room temperature for different periods. Figure 5A (a, b and c) for glass sample with $x=5 \mathrm{~mol} \%$ shows that the ditches on the surface go on increasing with immersion time due to attack of $\mathrm{H}^{+}$ions on the network. It appears that a new surface layer is formed due to the diffusion of $\mathrm{H}^{+}$ions after $20 \mathrm{~h}$ of exposure and dissolution of original layer (figure 5A.d). It is seen from figure $5 \mathrm{~B}$ ( $\mathrm{a}$ and $\mathrm{b}$ ) that, for glass sample with $x=10 \mathrm{~mol} \%$, there is a rapid increase in dissolution of the surface layer with few ditches forming on the surface. As regards the dissolution in acid medium, as $\mathrm{B}_{2} \mathrm{O}_{3}$ content in the glass increases, the $\mathrm{O} / \mathrm{P}$ ratio also increases and the bridging oxygens are converted into non-bridging oxygens. The dissolution rates increase as the phosphate chains get converted from meta phosphate $(\mathrm{O} / \mathrm{P}=3)$ to orthophosphate $(\mathrm{O} / \mathrm{P}=4 \cdot 0)$ structural units by hydration mechanism. Possible dissolution reactions are given in the following equations (Wen and Jijian 2001)

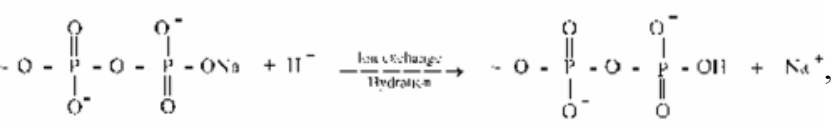<smiles>COP(=O)(OC)O[IH]P(=O)(O)OC</smiles>

$\left[\mathrm{BO}_{4}\right] \mathrm{Na}^{+}+2 \mathrm{H}^{+} \rightarrow \mathrm{H}_{3} \mathrm{BO}_{3}+\mathrm{NaOH}$.

Therefore, for $x=5$ mole $\%$ sample the metaphosphate chains containing less non-bridging oxygens are less corroded with $\mathrm{HCl}$, whereas the $x=10,15$ and $20 \mathrm{~mol} \%$ samples contain more non-bridging oxygens and are more corroded with $\mathrm{HCl}$. The phosphate chains are leached by hydration mechanism.

Figure 6 shows the weight loss (dissolution rate) of glass samples of various compositions in $5 \% \mathrm{NaOH}$ solution, at room temperature, as a function of immersion time.

It is evident that the dissolution rate initially decreases from $27.6 \mathrm{mg} / \mathrm{cm}^{2}$ to $17.4 \mathrm{mg} / \mathrm{cm}^{2}$ as $\mathrm{B}_{2} \mathrm{O}_{3}$ content is increased from $5 \mathrm{~mole} \%$ to $10 \mathrm{~mole} \%$. However, with further increase in $\mathrm{B}_{2} \mathrm{O}_{3}$ content to $15 \mathrm{~mole} \%$, it increases substantially from $17.4 \mathrm{mg} / \mathrm{cm}^{2}$ to $58 \mathrm{mg} / \mathrm{cm}^{2}$ after $205 \mathrm{~h}$ immersion time.

Figures 7A-D show photographs of the surface of various glass samples exposed to $5 \% \mathrm{NaOH}$ solution, at room temperature, for different periods.

As regards the dissolution in alkaline medium, in the glass sample with $x=5 \mathrm{~mol} \%, \mathrm{OH}^{-}$ions modify the meta- 

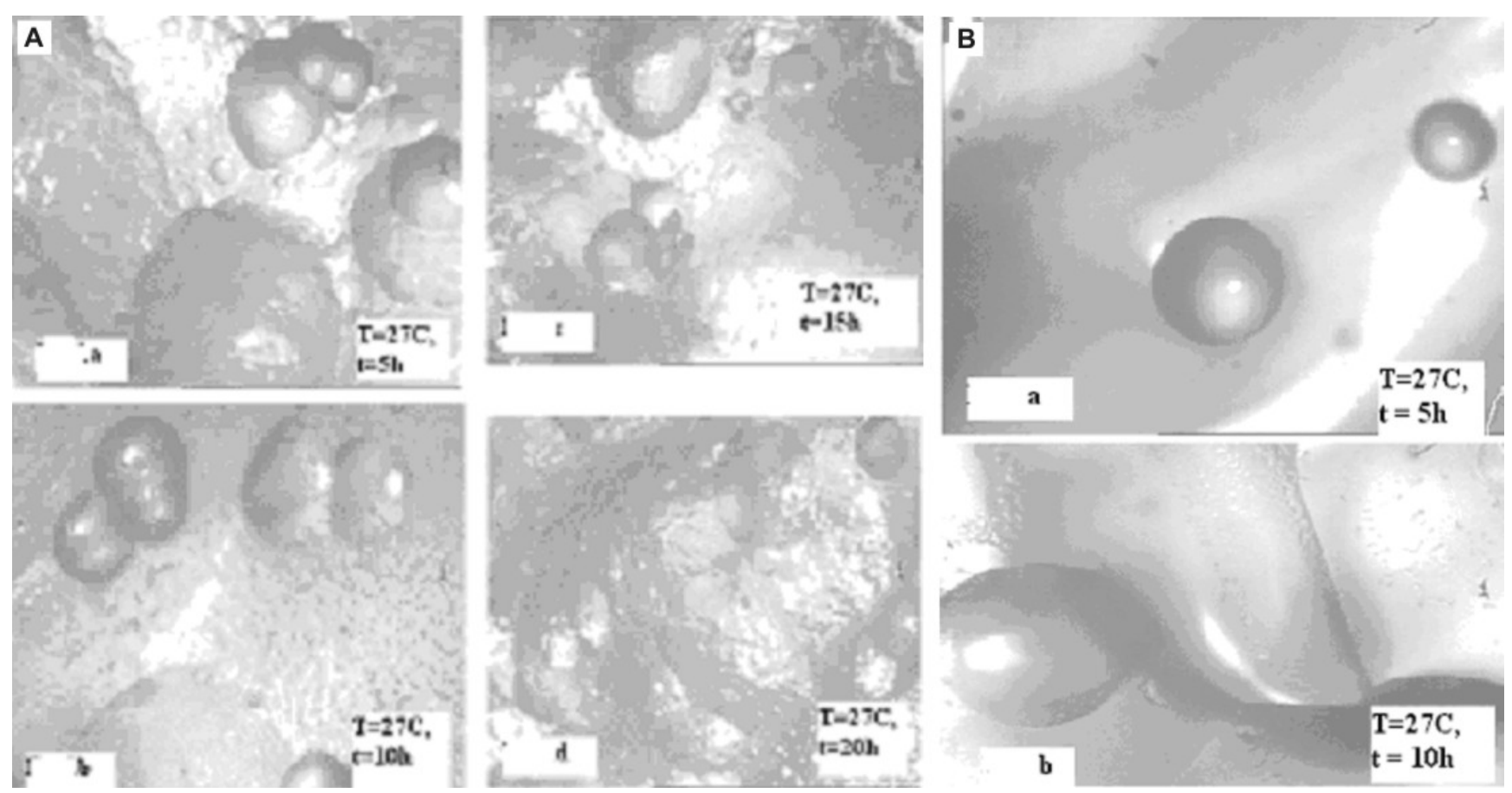

Figure 5. A. Photographs of $x=5 \mathrm{~mol} \%$ sample exposed to $5 \% \mathrm{HCl}$ solution at room temperature and at $25 \mathrm{X}$ magnification, and B. photographs of $x=10 \mathrm{~mol} \%$ sample exposed to $5 \% \mathrm{HCl}$ solution at room temperature and at $25 \mathrm{X}$ magnification.

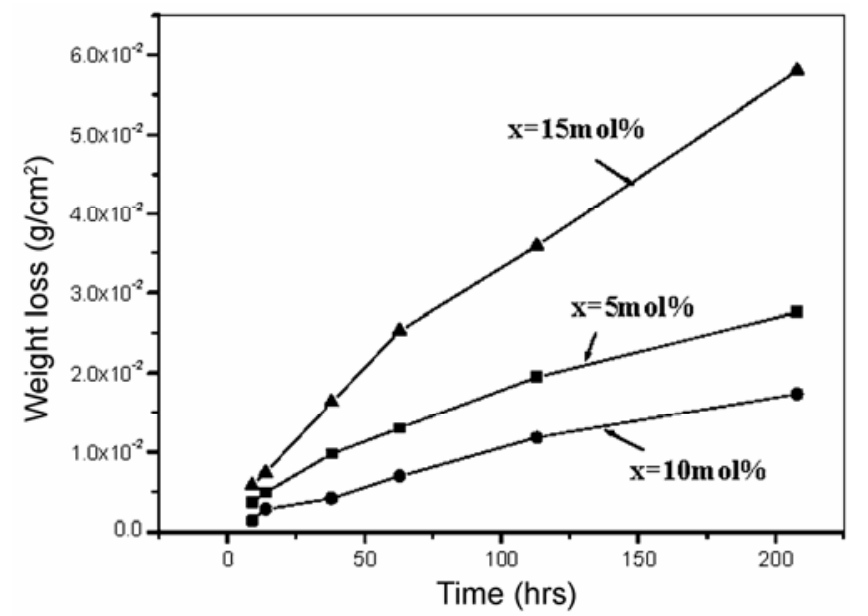

Figure 6. Dissolution of glass samples $(x=5-15 \mathrm{~mol} \%)$ in $5 \% \mathrm{NaOH}$ at room temperature.

phosphate network, as confirmed by ${ }^{31} \mathrm{P}$ MAS $\mathrm{NMR}^{12}$ (Shah et al 2005). The presence of less $\mathrm{BO}_{4}$ structural units and more $\mathrm{P}-\mathrm{O}-\mathrm{P}$ linkages results in the increase of weight loss. Whereas, for glass sample with $x=10 \mathrm{~mol} \%$, as $\mathrm{BO}_{4}$ structural units increase, more and more $\mathrm{P}-\mathrm{O}-\mathrm{B}$ bonds are formed at the cost of P-O-P bonds. Since $\mathrm{P}-\mathrm{O}-\mathrm{B}$ bonds are stronger as compared to $\mathrm{P}-\mathrm{O}-\mathrm{P}$ bonds, there is a decrease in the dissolution rate of the glass sample. It may be mentioned that although $\mathrm{O} / \mathrm{P}$ ratio is higher for the sample with $x=10 \%$, compared to that with $x=5 \%$, the dissolution rate is reduced, which may be attributed to the increase in the formation of $\mathrm{P}-\mathrm{O}-\mathrm{B}$ bonds. When $\mathrm{B}_{2} \mathrm{O}_{3}$ content further increases, i.e. $x=15$ and $20 \mathrm{~mol} \%, \mathrm{BO}_{3}$ structural units as well as the $\mathrm{O} / \mathrm{P}$ ratio increases. $\mathrm{As} \mathrm{BO}_{3}$ units are moisture sensitive, the dissolution rate increases with increase in $\mathrm{BO}_{3}$ units. Also $\mathrm{O} / \mathrm{P}$ ratio reaches to that of the orthophosphate structure, with a low $\mathrm{P}_{2} \mathrm{O}_{5}$ content dispersed in disordered borate network. These orthophosphate units readily dissolve in $\mathrm{NaOH}$ solution due to increase in non-bridging oxygen atoms and thereby increasing the dissolution rate as compared to glass samples with $x=5$ and $10 \mathrm{~mol} \%$. The possible reactions for the dissolution in alkali medium for orthophosphate glasses are as follows

$$
\begin{aligned}
& \mathrm{Na}_{3} \mathrm{PO}_{4}+\mathrm{NaOH}+3 \mathrm{H}_{2} \mathrm{O} \rightarrow \mathrm{H}_{3} \mathrm{PO}_{4}+4 \mathrm{NaOH}, \\
& \mathrm{B}_{2} \mathrm{O}_{3}+6 \mathrm{NaOH} \rightarrow 2 \mathrm{Na}_{3} \mathrm{BO}_{3}+3 \mathrm{H}_{2} \mathrm{O}
\end{aligned}
$$

The formation of ortho phosphoric acid and sodium borate also suggests increase in dissolution rates with exposure to alkali medium for higher $\mathrm{B}_{2} \mathrm{O}_{3}$ content samples ( $x=15$ and $20 \mathrm{~mol} \%$ glass samples).

The surface of as polished glass sample with $x=5 \mathrm{~mol} \%$ is smooth (figure 7A.a). As the immersion time increases from $3 \mathrm{~h}$ to $205 \mathrm{~h}$, the size of ditches formed on the surface increases, resulting in the increase in weight loss (figures 7A.b-7A.e). Whereas, the surface of the glass sample with $x=10 \mathrm{~mol} \%$ shows that the chemical attack is much less even after immersing for $205 \mathrm{~h}$ (figures 7B.b-B.g), which is consistent with weight loss observed (figure 6). The glass sample, $x=15 \mathrm{~mol} \%$, shows that 

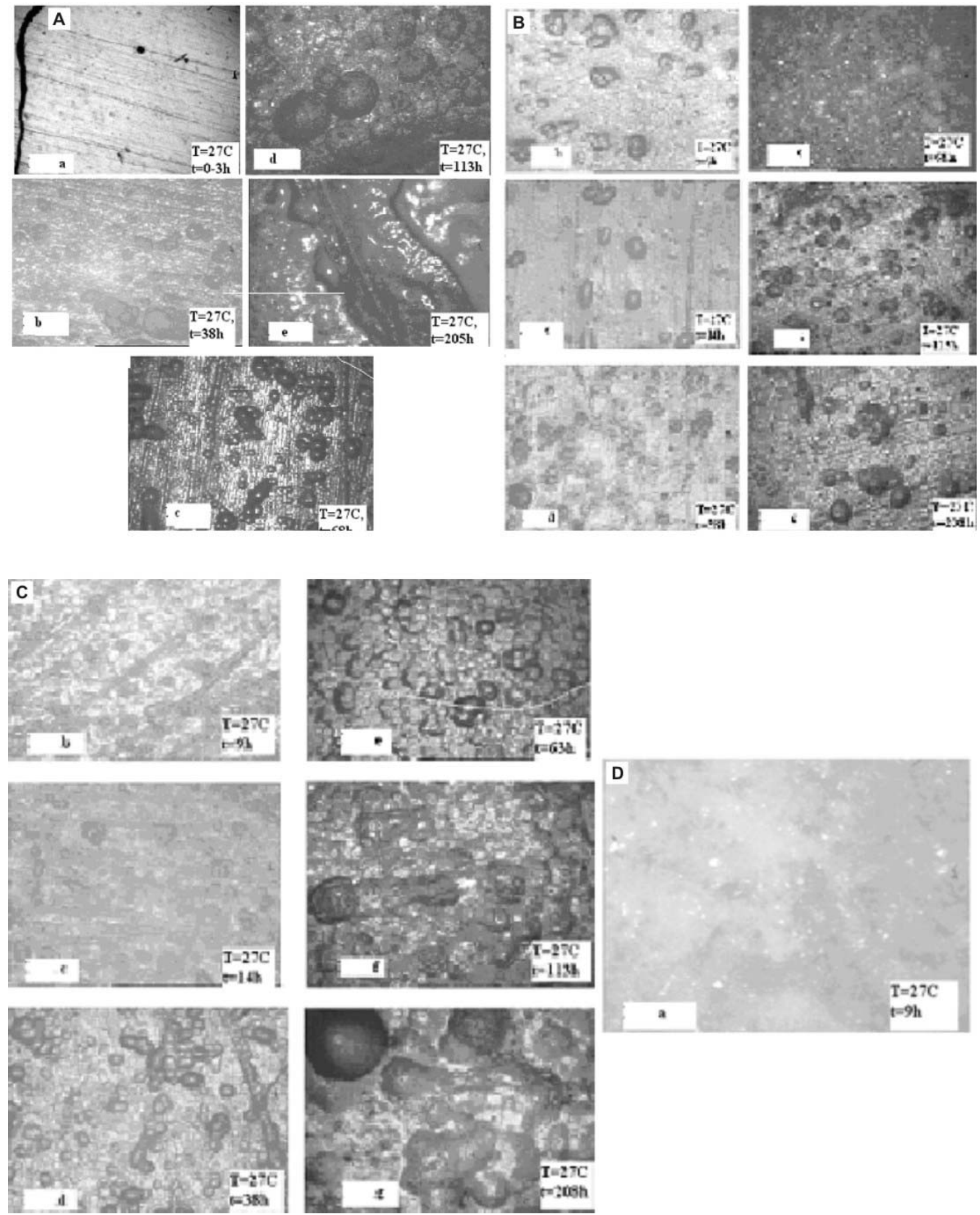

Figure 7. A. Photographs of sample with $x=5 \mathrm{~mol} \%$ exposed to $5 \% \mathrm{NaOH}$ solution at room temperature and at $25 \mathrm{X}$ magnification, B. photographs of sample with $x=10 \mathrm{~mol} \%$ exposed to $5 \% \mathrm{NaOH}$ solution at room temperature and at $25 \mathrm{X}$ magnification, C. photographs of sample with $x=15 \mathrm{~mol} \%$ exposed to $5 \% \mathrm{NaOH}$ solution at room temperature and at $25 \mathrm{X}$ magnification and D. photographs of sample with $x=20 \mathrm{~mol} \%$ exposed to $5 \% \mathrm{NaOH}$ solution at room temperature and at $25 \mathrm{X}$ magnification. 


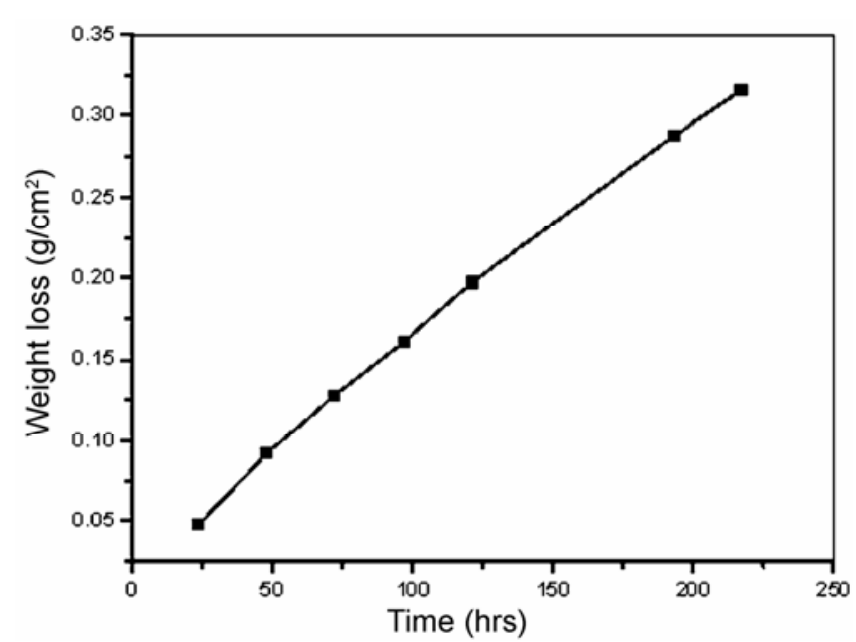

Figure 8. Dissolution of $x=10 \mathrm{~mol} \%$ glass sample in alkali medium at $60^{\circ} \mathrm{C}$.
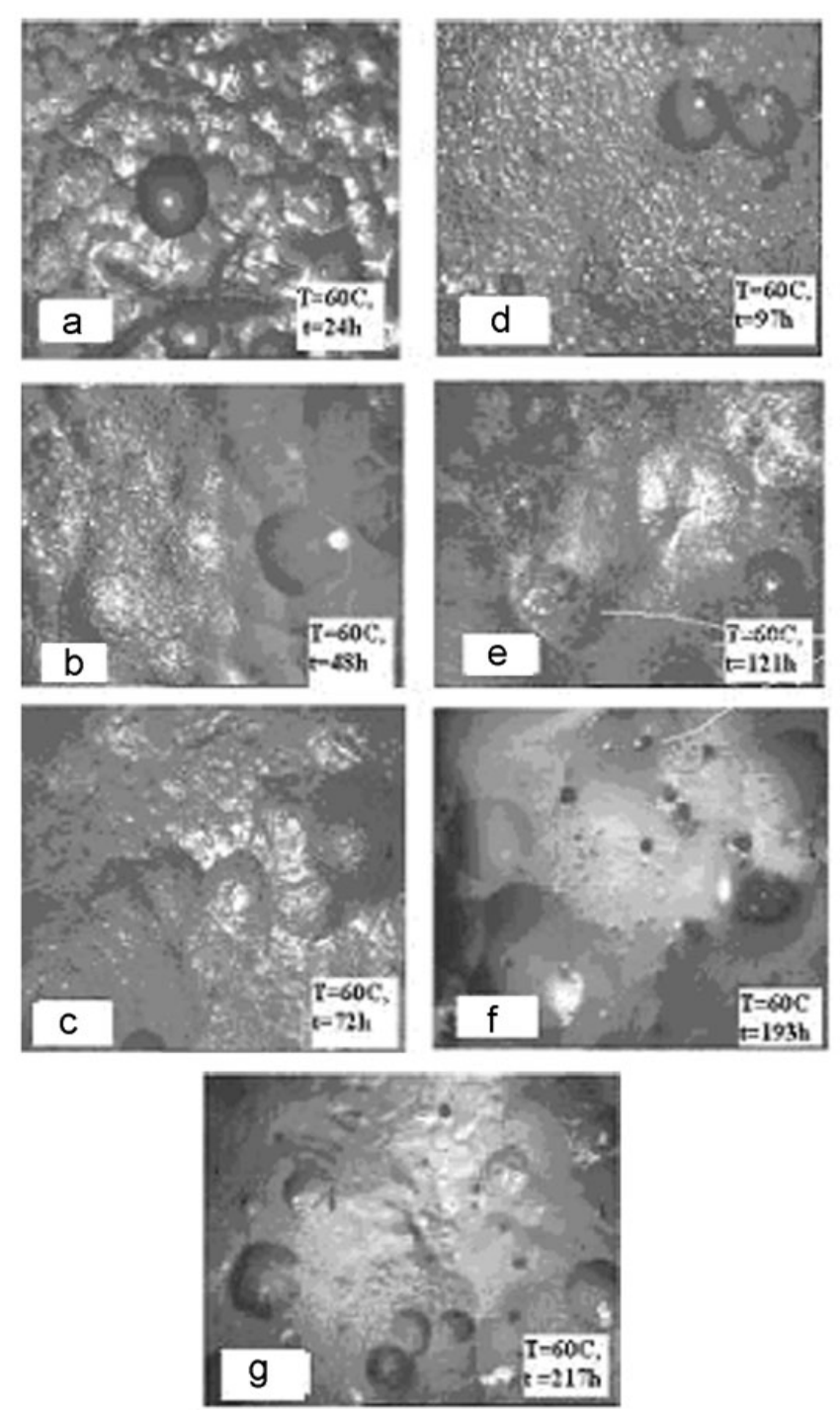

Figure 9. a-g. Photographs of continuous degradation of the surface of sample with $x=10 \mathrm{~mol} \%$, in $5 \% \mathrm{NaOH}$ at $60^{\circ} \mathrm{C}$ for different periods. there is a continuous degradation (increases in the size of ditches) of the surface with increase in immersion time (figures 7 C.b-7C.g). As $\mathrm{B}_{2} \mathrm{O}_{3}$ content is further increased to $20 \mathrm{~mol} \%$, there is a fast degradation of the surface and the sample is completely dissolved after $9 \mathrm{~h}$ immersion (figure 7D).

Figure 8 shows the dissolution rate (weight loss) of a glass sample of $x=10 \mathrm{~mol} \%$ in $5 \% \mathrm{NaOH}$ solution at $60^{\circ} \mathrm{C}$ as a function of immersion time. The dissolution rate increases linearly with immersion time. It is nearly twice compared to the weight loss at room temperature after $205 \mathrm{~h}$ immersion.

Figure 9 shows the photographs of the surface of the glass sample with $x=10 \mathrm{~mol} \%$ glass sample exposed to $5 \% \mathrm{NaOH}$ solution at $60^{\circ} \mathrm{C}$ for different periods. Figures $9 \mathrm{a}-\mathrm{e}$ show continuous degradation of the surface and the weight loss with the formation and growth of ditches on the surface in between 24 and $97 \mathrm{~h}$ of exposure. Figure $9 \mathrm{f}$ shows the total leaching of the surface layer, which is consistent with significant increase in weight loss between 121 and $193 \mathrm{~h}$ of exposure. The surface is further degraded after $217 \mathrm{~h}$ with the increase in diffusion rate at $60^{\circ} \mathrm{C}$.

The dissolution rates are controlled by diffusion process, which is affected remarkably by temperature. With the increase in temperature, the effect of diffusion rate on dissolution rate is significant as seen in figure 8 . Similar abnormal and complicated trend of change of dissolution rates in borophosphate glasses with relatively higher sodium content has been observed by Gao et al (2004).

\section{Conclusions}

Bubble free glasses of sodium barium borophosphate, $40 \mathrm{Na}_{2} \mathrm{O}-10 \mathrm{BaO}-x \mathrm{~B}_{2} \mathrm{O}_{3}-(50-x) \quad \mathrm{P}_{2} \mathrm{O}_{5} \quad(0 \leqslant x \leqslant 20 \mathrm{~mol} \%)$, were prepared. At low $\mathrm{B}_{2} \mathrm{O}_{3}$ content, the durability (degradation behaviour) of these glasses in water, acid and alkali medium is improved. However, at higher $\mathrm{B}_{2} \mathrm{O}_{3}$ content, the dissolution rates are increased. All the glasses were found to be fairly stable in alkali and water medium than acid medium. However, the glass sample, $x=10 \mathrm{~mol} \%$, was found to be more stable than the other glasses in all media at room temperature and at $60^{\circ} \mathrm{C}$.

\section{Acknowledgements}

The authors would like to thank Drs V C Sahni and J V Yakhmi for their constant support and encouragement to this work. They acknowledge the useful technical discussions with Dr Sudarsan. The authors would also like to acknowledge Mr Arjun Sarkar, Mr Rakesh Kumar and Mr P A Wagh for technical assistance. One of the authors (KVS) would like to thank DAE for giving him a fellowship. 


\section{References}

Brow R K 1996 J. Non-Cryst. Solids 194267

Brow R K 2000 J. Non-Cryst. Solids 263 \& 2641

Brow R K and Tallant D R 1997 J. Non-Cryst. Solids 222396

Coppo D, Duclot M J and Souquet J L 1996 Solid State Ionics 90111

Gao H, Tan T and Wang D 2004 J. Controlled Release 921

Harish Bhat M, Berry M J, Jiang J Z and Rao K J 2001 J. NonCryst. Solids 29193

Kaushik R and Hariharan K 1987 Solid State Commun. 63925
Ma Y, Deoff M M, Visco M J and Jonghe De L C 1993 J. Electrochem. Soc. 1402726

Shah K V, Goswami M, Patil A S, Manikandan Shobha, Shrikhande V K and Kothiyal G P 2005 Solid State Phys. 50359

Shah K V, Goswami M, Deo M N, Sarkar A, Manikandan Shobha, Shrikhande V K and Kothiyal G P 2006 Bull. Mater. Sci. 2943

Tsuchiya T and Moriya T 1980 J. Non-Cryst. Solids 38-39 323

Wen L and Jijian C 2001 Glass Technol. 42153

Wilder J A 1980 J. Non-Cryst. Solids 3-39 879

Yun Y H and Bray P J 1978 J. Non-Cryst. Solids 3045 